\title{
Metal Mesh Smear Sampling for Glow Discharge Analytical Spectroscopy
}

\author{
R. W. Shaw \\ C. M. Barshick \\ J. M. Ramsey \\ D. H. Smith \\ Chemical and Analytical Sciences Division \\ Oak Ridge National Laboratory \\ Oak Ridge, Tennessee
}

June 2000 
National Security Program Office

\title{
Metal Mesh Smear Sampling for Glow Discharge Analytical Spectroscopy: Interim Technical Report
}

\author{
R. W. Shaw \\ C. M. Barshick \\ J. M. Ramsey \\ D. H. Smith \\ Chemical and Analytical Sciences Division \\ Oak Ridge National Laboratory
}

\author{
Prepared by \\ National Security Program Office \\ Oak Ridge Y-12 Plant \\ Oak Ridge, Tennessee 37831-8260 \\ managed by \\ Lockheed Martin Energy Systems, Inc. \\ for the \\ U.S. Department Of Energy \\ under Contract DE-AC05-84OR21400
}




\section{DISCLAIMER}

This report was prepared as an account of work sponsored by an agency of the United States Government. Neither the United States Government nor any agency thereof, nor any of their employees, makes any warranty, express or implied, or assumes any legal liability or responsibility for the accuracy, completeness, or usefulness of any information, apparatus, product, or process disclosed, or represents that its use would not infringe privately owned rights. Reference herein to any specific commercial product, process, or service by trade name, trademark, manufacturer, or otherwise, does not necessarily constitute or imply its endorsement, recommendation, or favoring by the United States Government or any agency thereof. The views and opinions of authors expressed herein do not necessarily state or reflect those of the United States Government or any agency thereof. 


\section{Contents}

Page

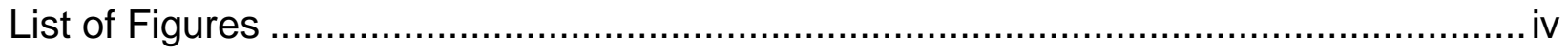

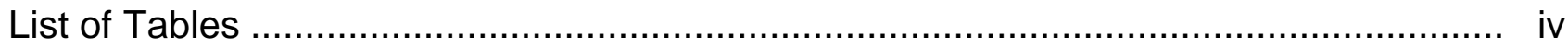

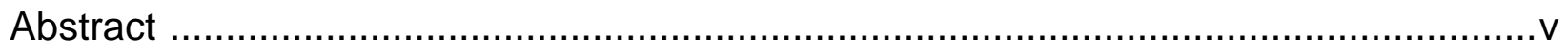

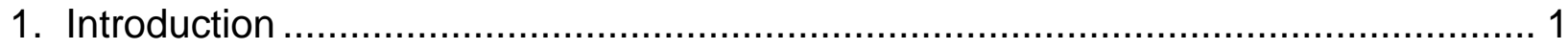

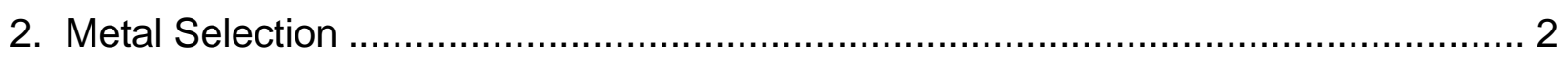

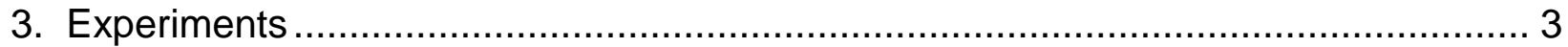

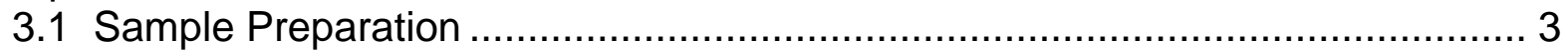

3.2 Optical Emission Experiments …............................................................ 3

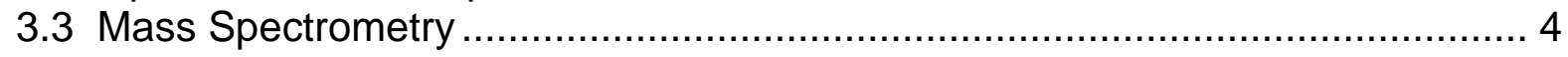

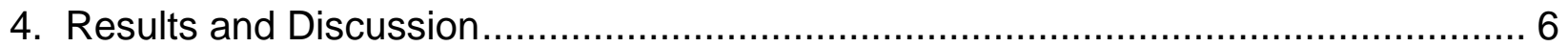

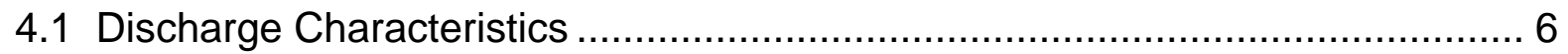

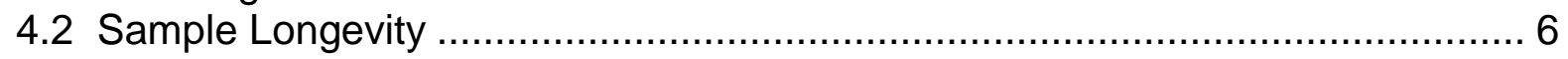

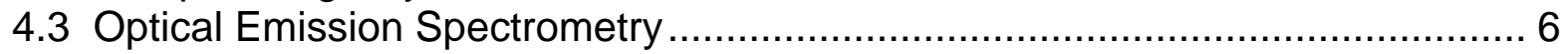

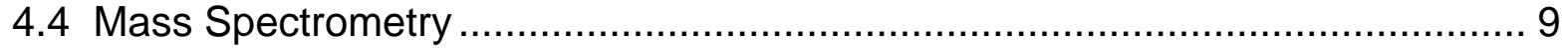

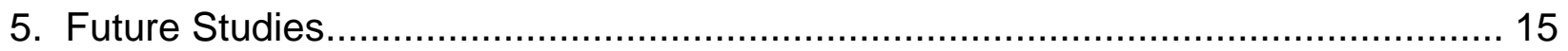

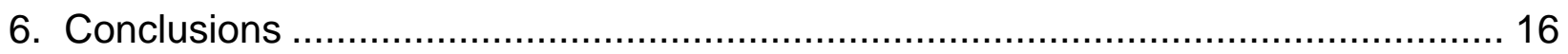

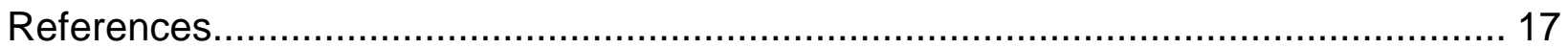




\section{List of Figures}

No.

Page

1 Hollow cathode insertion probe for optical spectroscopy............................... 4

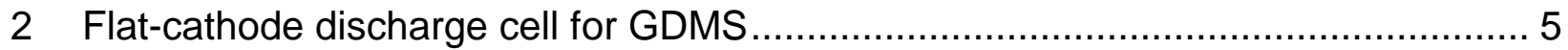

3 A 3-nm portion of the glow discharge spectrum for $180-\mu \mathrm{g}$ aluminum loaded on a

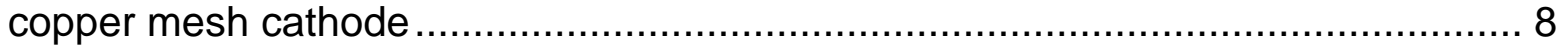

4 Uranium 238 ion current and calculated ${ }^{235} \mathrm{U} /{ }^{238} \mathrm{U}$ isotope ratio as a function of time for $100-\mu \mathrm{g}$ uranium loaded onto a copper mesh cathode and measured using

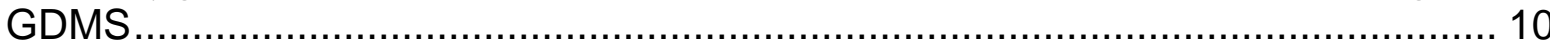

5 Linear working curve for uranium enrichments, as measured using GDMS......... 11

\section{List of Tables}

No.

1 Metal samples available for testing 2

2 Intense uranium emission lines, originating energy level, isotope shift, and interfering argon or copper emission lines

3 Uranium content of commercial metal mesh samples as determined using TIMS. 10

4 Glow discharge mass spectrometric analyses of copper mesh smears of radiological gloveboxes

5 Comparison of uranium analyses for radiological glovebox smears using GDMS, TIMS of a separate portion of each loaded mesh sample (TIMS-1), and TIMS of the same portion of the loaded mesh initially used for GDMS (TIMS-2) 13

6 Uranium analyses for smears of painted surfaces 


\begin{abstract}
Metal mesh smear sampling is being developed and evaluated for use in a number of glow discharge and other optical and mass spectrometric techniques. Sensitive elemental and isotopic analyses thus will be coupled with a convenient sampling scheme similar to one that is common for radiological surveys.
\end{abstract}





\section{INTRODUCTION}

Smear (or swipe) sampling is standard for ra diologic al mea surements. This technique is the centerpiece of all health physic s surveys and involves removing material from a surface by wiping with a paper or cloth swipe. For radiological mea surements, these samples a re counted using an instrument that accepts the swipe medium directly. Using this approach for typic al surfaces (e.g., painted walls, metal beams, etc.), removal of more than a few mic rograms of material from the surface is not expected.

Radiological counting only provides information concerning radionuclides, and even then it may not be pertinent for many analysis challenges. For example, the only result possible from disintegration counting (without more sophisticated instrumentation) is the total sample activity. That measurement, however, does not provide information concerning the relative isotopic abundances for a mixture of radionuclides that might be present in the sample. To ascertain an isotope ratio, mass spectrometric analysis of the smear sample usually is required. Mass spectrometry can be time consuming and expensive when conventional sampling methods are used, especially when sample dissolution is required.

The use of metal meshes as swipe media is being explored. The goal is to use this sampling medium in conjunction with a variety of glow discharge techniques. In addition, secondary ion mass spectrometry (SIMS) and laser ablation techniques, using these media, are under investigation. These meshes potentially will remove more sample material from a surface than conventional cloth or paper media. Moreover, neither cloth nor paper is compatible with the glow discharge. Metal mesh swipes should interface conveniently with several glow discharge analytical methods and, thus, serve as a multipurpose sampling technique. The sampling mesh would be pressed or otherwise formed into a cathode. The family of glow discharge spectroscopies that could benefit from this development includes optical emission spectroscopy, laser induced fluorescence, optogalvanic spectroscopy, and mass spectroscopy. All of these techniques can provide quantitative analytical determinations for the constituents of the sample material captured, and several of them can provide a simultaneous isotopic analysis.

In addition to their use in glow discharge measurements, loaded metal mesh samples can be counted using standard radiological methods and/or be dissolved for thermal ionization mass spectrometry (TIMS). A metal mesh also may serve as a superior medium for SIMS or laser ablation techniques. Therefore, metal mesh samples can be subjected to a battery of methods to extract as much information as possible concerning the sampled surface.

Many of the advantages of swipe sampling would be sacrificed if it were necessary to remove the sample from the swipe medium before conducting an analysis. The goal, then, is to analyze the loaded mesh without removing the sample. No chemical processing is envisioned. 


\section{METALSEIECTION}

The metal mesh (or gauze) materials selected for this study are fabricated from soft metals to aid in cathode fabrication. Ideally, the metal selected should be malleable and available in a pure form to minimize contamination of the discharge with interfering elements that might present spectral interferences. Ideally, the mesh would be inexpensive. Copper is a candidate mesh with many of these properties. Moreover, copper exhibits a high sputtering yield in our discharge, so the introduction of analyte into the gas phase is rapid.

To find the metal meshes available commercially, a survey was conducted, and a collection of candidate media was ordered, including mesh materials, some foils, and a wool. The materials on hand are summarized in Table 1.

Table 1. Metal samples available for testing.

\begin{tabular}{|l|l|l|l|l|}
\hline \multicolumn{1}{|c|}{ Metal } & \multicolumn{1}{|c|}{ Purity } & \multicolumn{1}{c|}{ Form } & \multicolumn{1}{c|}{ Dimensions $^{a}$} & \multicolumn{1}{c|}{ Source $^{b}$} \\
\hline Silver & $99.98 \%$ & Mesh & $80 / 0.0045 \mathrm{in.}$ & Alfa-Aesar \\
Silver & $99.998 \%$ & Foil & $0.001 \mathrm{in}$. & Alfa-Aesar \\
Silver & $99.9+\%$ & Wool & $0.05 \times 25-\mathrm{mm}$ fibers & Aldrich \\
& & & & \\
Gold & $99.9 \%$ & Mesh & $100 / 0.0025 \mathrm{in}$. & Alfa-Aesar \\
Gold & $99.99 \%$ & Foil & $0.001 \mathrm{in.}$ & Alfa-Aesar \\
& & & & \\
Copper & Unknown & Mesh & $50 / 0.009 \mathrm{in}$. & Alfa-Aesar \\
Copper & $99.999 \%$ & Foil & $0.001 \mathrm{in.}$ & Aldrich \\
Indium & $99.999 \%$ & Foil & $0.1 \mathrm{~mm}$ & Aldrich \\
\hline
\end{tabular}

${ }^{a}$ For mesh samples, mesh (i.e., wires/in.)/wire diameter; for foil samples, thickness.

${ }^{b}$ Alfa-Aesar

30 Bond St.

Ward Hill, MA 01835-8099

(978/521-6300)
Aldrich Chemical Co.

1001 West St. Paul Ave.

Milwaukee, WI 53233

(414/273-3850) 


\section{EXPERIMENTS}

\subsection{Sample Preparation}

Samples were fashioned using one of two methods. For initial quantitative measurements, solutions of analytes were prepared and a known amount of the solution was pipetted onto a blank mesh. The loaded mesh was subsequently dried before analysis. This method allowed loading of a known quantity of analyte. The alternative loading method is more similar to real-world sampling but is essentially nonquantitative at this time. A residue of an analyte solution was prepared on a solid surface (e.g., painted metal), and a mesh blank was rubbed by hand against the surface to capture some of the analyte in the mesh metal and voids. In some cases, the surfaces used for this latter loading method were actual glovebox interior walls at an Oak Ridge National Laboratory (ORNL) radiochemical facility.

\subsection{Optical Emission Experiments}

The optical experiments conducted were accomplished using a discharge cell fabricated from a vacuum cube fitted with 1.33-in. flanges (see reference 1). The cell accepted a direct insertion probe for ease of installation and removal of the mesh cathodes. The nickel tip of the probe was slotted to accept a $9 \times 17 \mathrm{~mm}$ metal mesh, which was then bent into the form of a hollow cylinder with a 2-3 mm diameter. A sketch of the cathode geometry is shown in Fig. 1. The discharge carrier gas was highpurity argon (2 Torr at a low flow rate). Needle valves were used in conjunction with the gas supply and vacuum pump to control the flow rate and cell pressure, respectively. The cathode high voltage was applied through a 18.7-kohm ballast resistor. The stainless steel vacuum cube served as the discharge anode. Typical voltage and current conditions were $500 \mathrm{~V}$ applied and $13 \mathrm{~mA}$.

The discharge emission was collected using a lens pair and was imaged onto the slit of a $0.5-\mathrm{m}$ focal length spectrograph, fitted with a $512 \times 512$ pixel charge-coupled device (CCD) detector operated at room temperature.

The dispersion of the polychromator and the CCD lateral dimension produced spectra spanning $23 \mathrm{~nm}$. The nominal spectral resolution typically was $0.1 \mathrm{~nm}$. The vertical pixel columns were summed to yield spectra. 


\section{Hollow Cathodes from Metal Mesh Media}

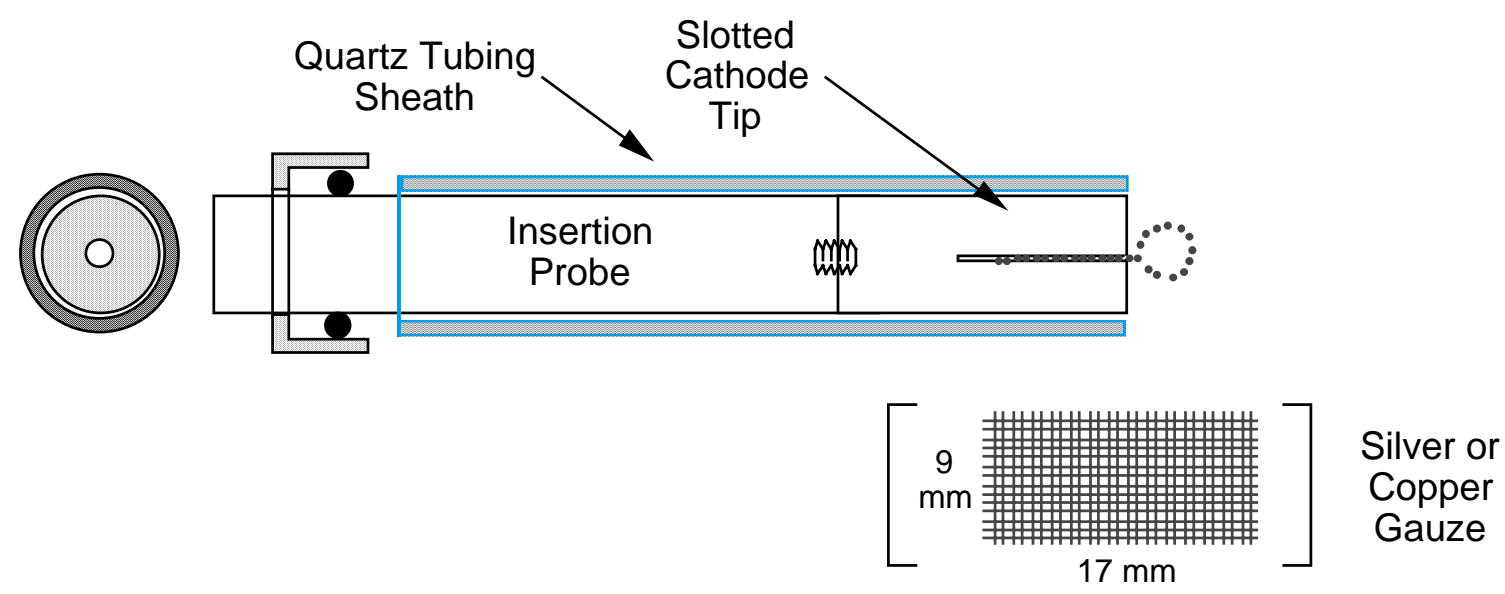

Fig. 1. Hollow cathode insertion probe for optical spectroscopy. An approximately $9 \times 17 \mathrm{~mm}$ portion of metal mesh (copper or silver) was inserted into a slotted cathode tip (nickel) and coiled to form a hollow cylinder with a 2-3 mm diameter. The probe was vacuum-sealed to the cell via an O-ring fitting. The discharge emission was viewed along the cathode cylinder axis.

\subsection{Mass Spectrometry}

Mass spectra were acquired using a VG9000 magnetic sector glow discharge mass spectrometer (VG Elemental, Winsford, Chesire, England). This instrument is capable of $9000 \mathrm{M} /$ )M resolution and has a 1-300 mass range at $8000 \mathrm{~V}$. The instrument was fitted with an ORNL-designed and fabricated flat cathode cell. The mesh media were compressed against a ceramic standoff by a high-purity copper cathode. A schematic drawing of the cell for glow discharge mass spectrometry (GDMS) is shown in Fig. 2. Typical operating conditions were 1 Torr argon, 1000-V applied potential, and 0.2-mA current. The discharge ions produced were sampled through a differentially pumped orifice to the mass spectrometer. 


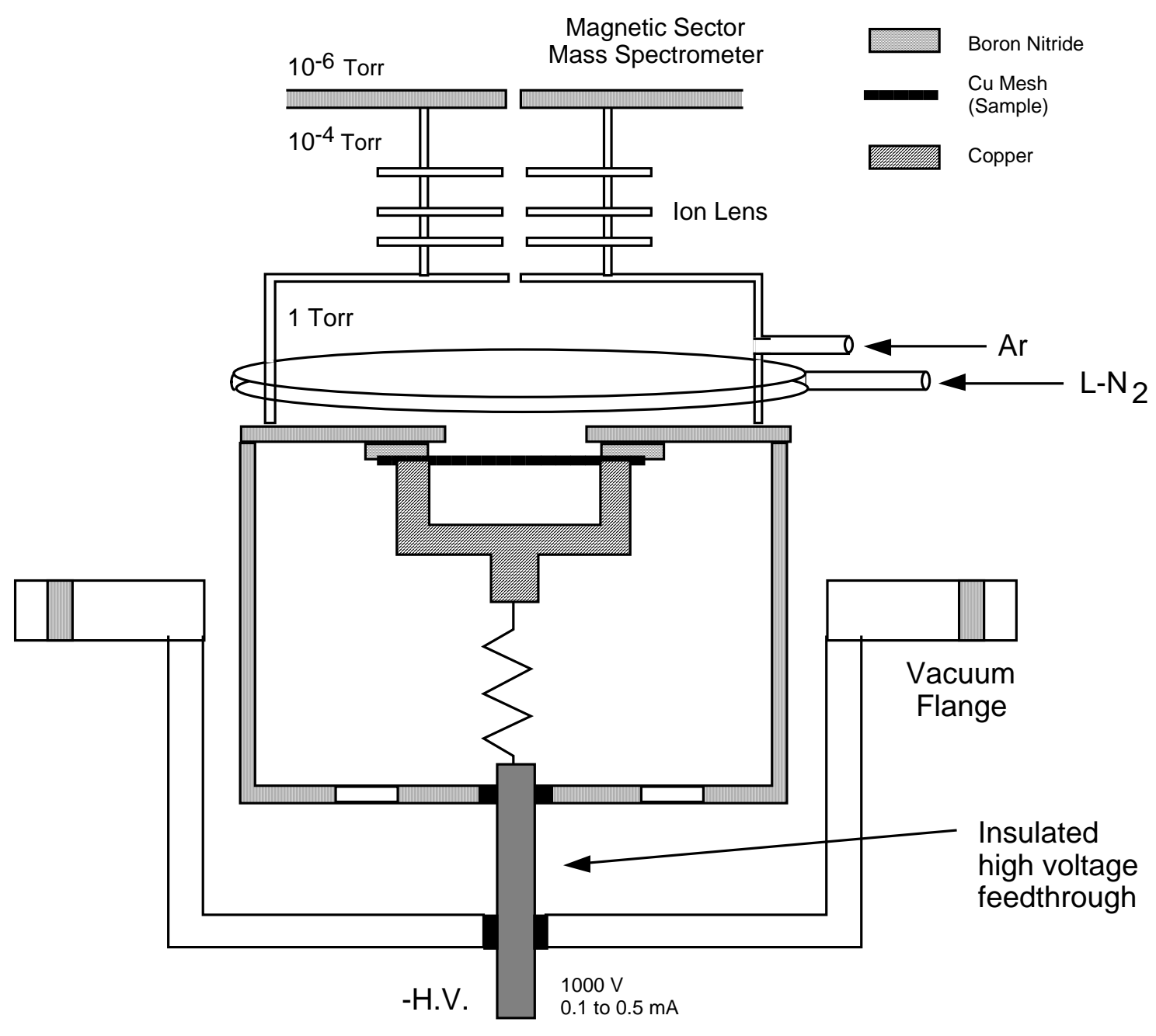

Fig. 2. Flat-cathode discharge cell for GDMS. A metal mesh (approximately $25 \times 25$ $\mathrm{mm}$ ) was pressed between a ceramic standoff (boron nitride) and a spring-loaded, cupped cathode. The glow discharge formed between the mesh and the tantalum cell body (at ground potential), which was liquid-nitrogen-cooled. The flat cell assembly was mounted inside the source housing of the VG9000, in place of the conventional pin cell assembly. lons were extracted through an orifice into the ion lens of the mass spectrometer.

Reference TIMS were acquired using a hot filament magnetic sector mass spectrometer of local design and construction. Samples were dissolved in nitric acid, spiked with an internal ${ }^{233} \mathrm{U}$ isotope dilution marker, separated via column chromatography, and loaded onto filaments for analysis. 


\section{RESULTS AND DISCUSSION}

\subsection{Discharge Characteristics}

At the outset of this project, we had no experience with high-surface-area cathodes and did not know how such a cathode might affect discharge operation. An experiment was conducted to determine if open mesh cathodes yield sufficiently stable discharges to permit our spectroscopic measurements. A copper mesh was mounted as the cathode in a discharge cell, and the AC component of the cathode voltage was monitored using a digital oscilloscope. That signal represents the electrical noise level for any electronic measurement (e.g., optogalvanic spectroscopy). Any arc formation due to the high fields near the mesh wire points would be detected as large, rapid excursions in the cathode voltage. The signal recorded showed a 6-mV peak-to-peak amplitude, about the same as that common for solid-slug cathodes. Arc formation was not observed.

\subsection{Sample Longevity}

Earlier glow discharge research conducted in our laboratory concerned solid-slug sample cathodes that contained the analyte throughout the cathode mass; these cathodes resulted in a steady release of analyte to the discharge via sputtering. An important challenge for the open-mesh cathode concept is that it is necessary for the sample to persist on the mesh surface for a time at least as long as required for an analysis. If the sample were to flash from the surface quickly, measurements would not be possible. A study of sample longevity for mesh discharge cathodes was undertaken as part of this effort. The results follow.

\subsection{Optical Emission Spectrometry}

Spontaneous emission spectrometry is a simple method that has been widely used for glow discharge techniques (see reference 2). It is one of a multitude of analytical methods that should be amenable to metal mesh sampling. Energetic discharge ions are accelerated into the cathode and sputter analyte atoms (as well as cathode mesh atoms) into the low-pressure vapor phase for atomic spectroscopy at modest resolution. Some of the sputtered analyte atoms are formed as excited states or are excited via collisions with energetic carrier gas atoms. In either case, the excited atoms relax by emitting light at characteristic wavelengths, which is monitored for qualitative and semiquantitative analysis.

One of the key target analyte atoms is uranium, an element well known for its ability to getter oxygen. This property will potentially limit our glow discharge/optical emission sensitivity if the discharge uranium atoms find an oxygen source and combine to form species such as $\mathrm{UO}_{2}$. Thus, as a surrogate atom, we selected aluminum, which also has a strong affinity for oxygen. A copper mesh was loaded using an $\mathrm{AlCl}_{3}$ solution $(180-\mu \mathrm{g}$ aluminum loaded) and dried under a heat lamp. The loaded mesh sample then was mounted on the insertion probe and formed into a cylindrically shaped hollow 
cathode, as described previously. A spectral region encompassing the 396.15-nm aluminum line was recorded as a function of time after initiation of the discharge. The atomic line strength is shown in Fig. 3, with spectra shown for acquisitions between 2 and 85 min. Several argon emission lines also are shown and demonstrate the stability of the discharge. A complication for analysis of the Fig. 3 aluminum data is that the declining line strength is accompanied by a decreasing discharge current. Thus, the apparent signal falloff is derived not only from the loss of analyte from the mesh but also from the changing discharge conditions. The discharge current sets the sputtering yield and, hence, the number density of excited aluminum atoms in the gas phase. For a quantitative measurement, both the optical signal and the discharge current must be recorded, and the former must be normalized using the latter. The mechanism responsible for the changing discharge current is unknown and may involve both thermal and gas composition effects. At $t=0$, the gas is ultrapure argon, and with the passage of time, the gaseous metal content increases. After about $30 \mathrm{~min}$, both the discharge current and the aluminum line strength stabilized and persisted for more than $1-1 / 2 \mathrm{~h}$. Thus, it can be seen that a rapid loss of sample via sputtering from the mesh did not occur, and ample time is available for analysis.

To determine the sensitivity of this method, another mesh was loaded with aluminum at a lower loading (8- $\mu$ g aluminum). A weaker signal was recorded, but it was still sufficient for quantification. In this case, the aluminum signal persisted for approximately $15 \mathrm{~min}$.

Candidate lines for uranium analysis were evaluated. Lines were selected using the Los Alamos National Laboratory (LANL) uranium emission line list (see reference 3). Only strong lines with a reported emission relative intensity above 200 or a particularly large ${ }^{235} \mathrm{U}^{238} \mathrm{U}$ isotope shift were considered. The candidate lines are listed in Table 2, which also shows the energy of the upper level of the transition and the nearest interfering copper and/or argon atomic line.

The listed line positions were investigated for a copper mesh/argon discharge, and those indicated with an "asterisk" were found to be suitable for uranium analysis using the optical emission technique. All observed interfering lines were at least one line width away. We have not yet conducted any uranium analyses by glow discharge emission spectrometry in our laboratory. Several of the tabulated lines exhibit large isotope spectral shifts, but none would be amenable for isotopic analysis. For example, the $-420 \mathrm{mcm}^{-1}$ shift for the $776.2-\mathrm{nm}$ line corresponds to $0.025 \mathrm{~nm}$. For our experimental arrangement, this is 0.6 pixels, which is too small to be of use. A higher-resolution spectrograph would be required for isotopic analysis. 


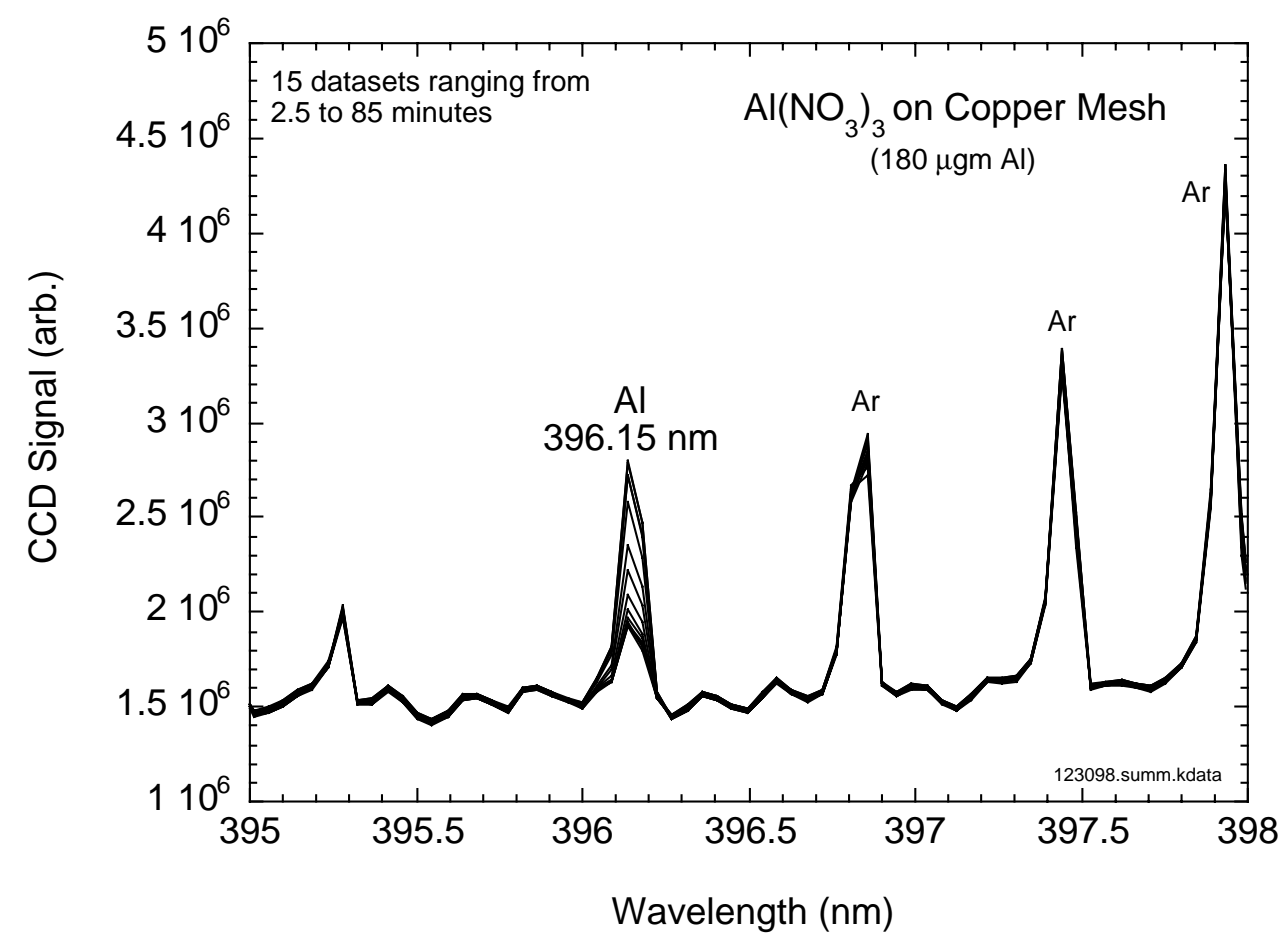

Fig. 3. A 3-nm portion of the glow discharge spectrum for $180-\mu \mathrm{g}$ aluminum loaded on a copper mesh cathode. The 396.15-nm aluminum line is apparent and decays with time. Stable argon carrier gas lines also are observed. Fifteen data sets are plotted. They were acquired over a time period from 2.5 to $85 \mathrm{~min}$. 
Table 2. Intense uranium emission lines, originating energy level, isotope shift, and interfering argon or copper emission lines. (Uranium lines indicated with an asterisk are free of spectral interference.)

\begin{tabular}{|c|c|c|c|c|c|}
\hline $\begin{array}{l}\text { Wavelength } \\
\text { (nm) }\end{array}$ & $\begin{array}{l}\text { Emission } \\
\text { intensity }\end{array}$ & $\begin{array}{l}\text { Upper } \\
\text { level } \\
\left(\mathrm{cm}^{-1}\right)\end{array}$ & $\begin{array}{l}\text { Isotope } \\
\text { shift }^{a} \\
\left(\mathrm{mcm}^{-1}\right)\end{array}$ & $\begin{array}{l}\text { Nearby } \\
\text { argon } \\
\text { line }\end{array}$ & $\begin{array}{l}\text { Nearby } \\
\text { copper } \\
\text { line }\end{array}$ \\
\hline 875.78 & 282 & 12035 & & 876.2 & \\
\hline 869.13 & 279 & 11502 & & & \\
\hline $860.80^{*}$ & 912 & 11613 & 170 & 860.6 & \\
\hline 835.71 & 24 & 15831 & 387 & & \\
\hline 831.84 & 104 & 16294 & 337 & & \\
\hline 822.31 & 148 & 18406 & 347 & & \\
\hline $791.88^{*}$ & 38.2 & 16900 & -307 & & 793.3 \\
\hline $788.19^{*}$ & 323 & 18932 & 315 & 789.1 & 789.6 \\
\hline $778.42^{*}$ & 425 & 13463 & 100 & 779.9 & 777.9 \\
\hline $776.19^{*}$ & 30.4 & 19885 & -420 & & 777.9 \\
\hline 753.39 & 260 & 17070 & & 751.5 & \\
\hline 682.69 & 621 & 14643 & & 682.7 & \\
\hline $644.92^{*}$ & 389 & 16121 & & & 644.2 \\
\hline 639.54 & 259 & 15631 & & 638.5 & \\
\hline 591.54 & 572 & 16900 & & 591.2 & \\
\hline $502.74^{*}$ & 382 & 19885 & & 503.2 & 502.1 \\
\hline 463.16 & 235 & 21584 & & 462.8 & 464.9 \\
\hline 439.36 & 284 & 22754 & & 440.0 & 437.8 \\
\hline 436.21 & 303 & 22918 & & 436.4 & 437.8 \\
\hline 435.57 & 211 & 23572 & & 435.2 & 437.8 \\
\hline 415.40 & 229 & 24066 & & 415.9 & \\
\hline
\end{tabular}

\subsection{Mass Spectrometry}

We have analyzed the suite of commercial metal mesh materials accumulated. TIMS was used to determine the uranium content of each material to assess its utility for sampling purposes. The inherent uranium content sets the background level for each medium. The results are summarized in Table 3.

Several of these materials compare favorably with the cellulose swipes currently in use (2-10 ng U/g). Interestingly, the gold sample has a high uranium content.

Copper mesh media were solution-loaded with 100- $\mu \mathrm{g}$ uranium (natural abundance) and dried. The uranium isotope ratio was determined by monitoring the mass spectrometer ion currents for ${ }^{238} \mathrm{U}$ and ${ }^{235} \mathrm{U}$. The resulting calculated isotope ratios, as well as the ${ }^{238} \mathrm{U}$ ion current, are shown in Fig. 4. Twenty ratio determinations were made; the statistical mean value found was $7.32 \times 10^{-3}$, which is in good agreement with the $7.2 \times 10^{-3}$ known value. As was found in the optical emission experiments, the uranium signal persisted for more than $2 \mathrm{~h}$, ample time for analysis. 
Table 3. Uranium content of commercial metal mesh samples as determined using TIMS.

\begin{tabular}{|l|l|l|l|}
\hline Metal mesh & Vendor & Lot number & $\begin{array}{l}\text { Uranium content } \\
\text { (ng/g) }\end{array}$ \\
\hline Copper & Alfa & J31G13 & 0.5 \\
\hline Copper & Alfa & I10I22 & 4.0 \\
\hline Silver & Alfa & B27l10 & 0.9 \\
\hline Gold $(99.9 \%)$ & Alfa & J03H20 & 22 \\
\hline
\end{tabular}

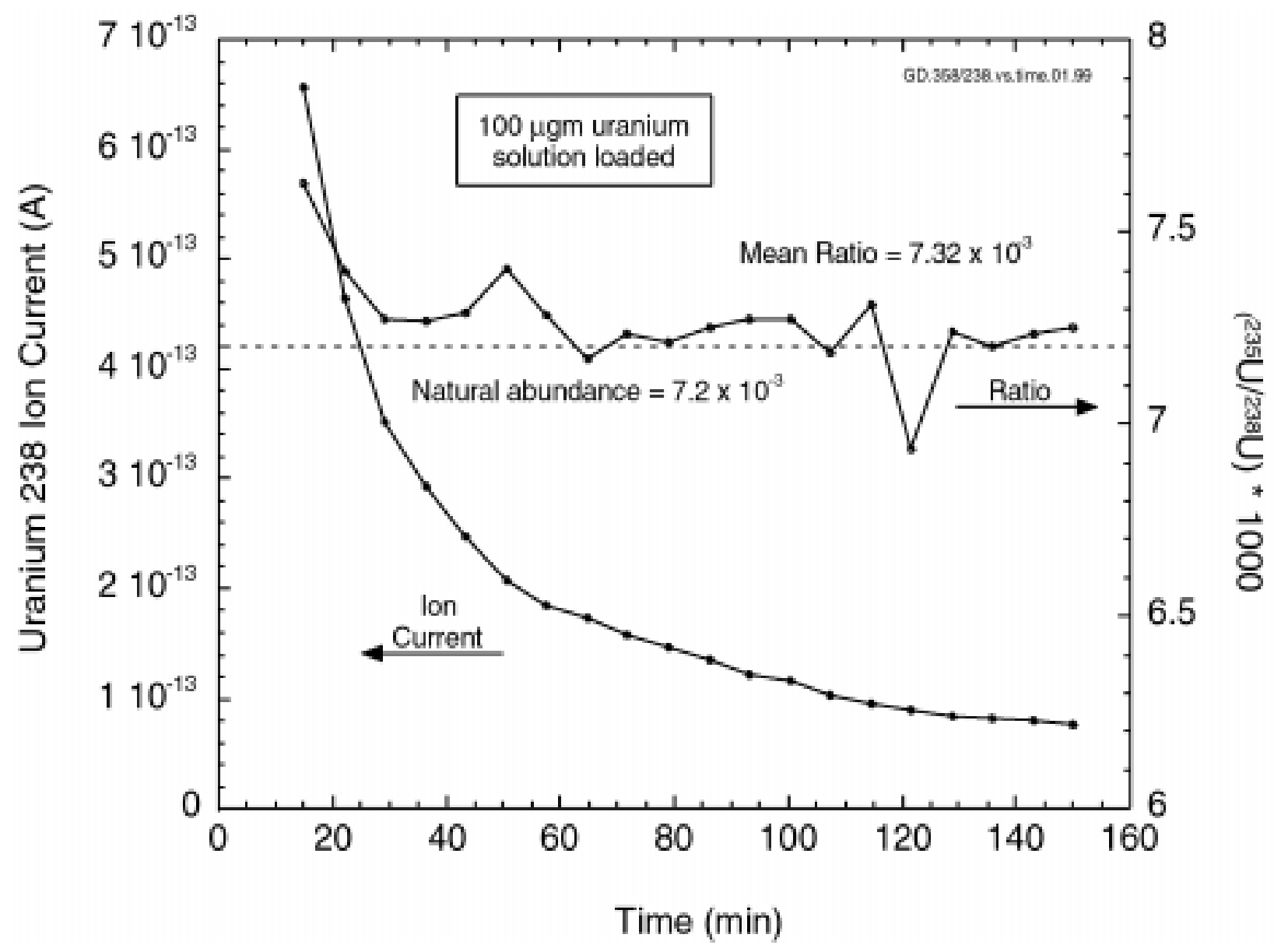

Fig. 4. Uranium 238 ion current and calculated ${ }^{235} \mathrm{U} /{ }^{238} \mathrm{U}$ isotope ratio as a function of time for $100-\mu \mathrm{g}$ uranium loaded onto a copper mesh cathode, as measured using GDMS. 
In a separate set of experiments, several National Institute of Standards and Technology (NIST) ura nium standards were a nalyzed at a va riety of enric hments ranging from ${ }^{235} \mathrm{U} /{ }^{238} \mathrm{U}=0.0051$ to 186.8 . Ura nium samples ( $50 \mu \mathrm{g}$ uranium) were solution-loaded onto copper mesh media, dried, and a nalyzed. The measured isotope ratios a re plotted aga inst the known values in Fig. 5. For the most demanding cases (i.e., the highest enric hments), the ratio measurement relative standard deviation was $\pm 1 \%$ to $\pm 3 \%$. We estimate from these results that, for a natural abundance sample, we could measure an isotope ratio to $1 \%$ precision for a 150-ng sample.

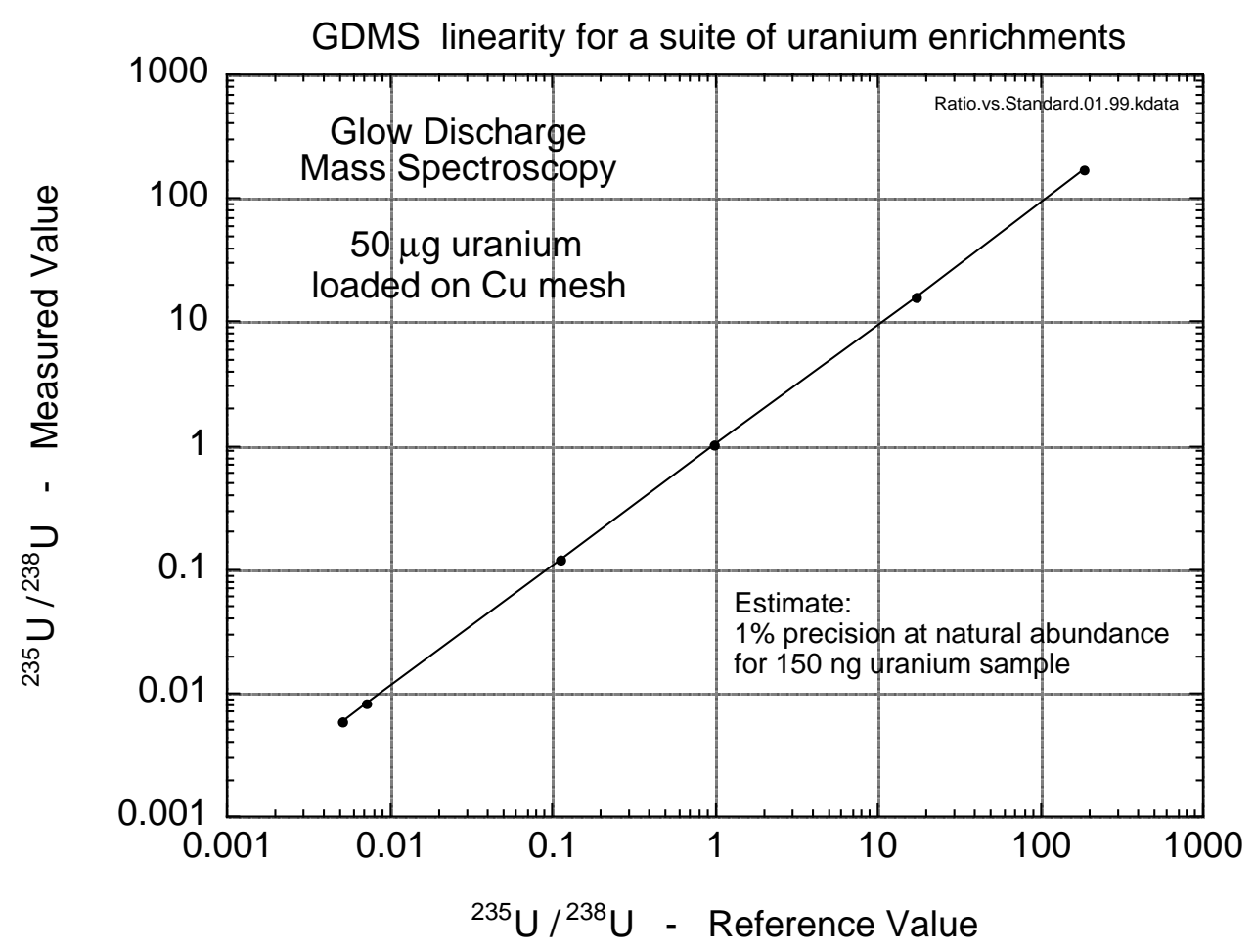

Fig. 5. Linear working curve for uranium enrichments, as measured using GDMS. Uranium standards $\left(50-\mu \mathrm{g}\right.$ uranium, each) with ${ }^{235} \mathrm{U} /{ }^{238} \mathrm{U}$ ratios ranging from 0.0051 to 186.8 were loaded onto separate copper mesh cathodes. The measured ratios are plotted versus the certified values for the standards.

In actual applications, metal mesh media will be loaded by smearing surfaces suspected of contamination and not loaded from solutions. To determine the sampling effectiveness for such an application, radiological gloveboxes were smeared using copper mesh media, and the resulting samples were analyzed using GDMS. The samples were purposefully chosen to range from inactive (sample "A," $84 \mathrm{dpm}$ alpha; 
$<200 \mathrm{dpm}$ beta/gamma) to moderately active (sample "C" 200,000 dpm alpha; 30,000 $\mathrm{dpm}$ beta/gamma). The mass spectrometric results are tabulated in Table 4. Cesium, actinium, thorium, and uranium were found. Where isotope ratios were determined, they are indicated in the table.

Table 4. GDMS analyses of copper mesh smears of radiological gloveboxes. ${ }^{a}$

\begin{tabular}{|c|c|c|c|c|}
\hline Sample & $\begin{array}{c}\text { Cesium } \\
\text { (ppb) }\end{array}$ & $\begin{array}{c}\text { Actinium } \\
(\mathrm{ppb})\end{array}$ & $\begin{array}{c}\text { Thorium } \\
\text { (ppb) }\end{array}$ & $\begin{array}{l}{ }^{238} \text { Uranium } \\
\text { (ppb) }\end{array}$ \\
\hline A & 90 & ND & 140 & 540 \\
\hline B & $\begin{array}{l}300 \\
(137 / 133=0.311)\end{array}$ & ND & $\begin{array}{l}550 \\
(230 / 232=0.032)\end{array}$ & 12.7 \\
\hline C & $\begin{array}{l}145 \\
(137 / 133=0.416)\end{array}$ & 375 & ND & 395 \\
\hline
\end{tabular}

${ }^{2}$ The concentrations indicated are relative to copper (assumed to be 100\%). Sample activities range from low level (A) to moderately active (C). Measured isotope ratios are shown in parentheses. (ND $=$ not determined.)

To more carefully analyze the samples, they were subjected to TIMS, with emphasis on the uranium isotopic abundances. The sampling mesh was cut into two pieces, with one part subjected to GDMS analysis (above). The other part was dissolved, spiked with a ${ }^{233} \mathrm{U}$ spike, separated using column chromatography (to isolate the uranium), and analyzed using TIMS. Substantial differences were observed for the two methods, and the results are summarized in Table 5 (where the TIMS data are indicated as "TIMS-1"). For example, the total uranium content of Sample A was 0.59 ppm by GDMS and $0.027 \mathrm{ppm}$ by TIMS. The isotopics differed as well; for example, for the same sample, the ${ }^{235} \mathrm{U} /{ }^{238} \mathrm{U}$ ratios were 0.0999 (GDMS) and 0.0059 (TIMS). The concentrations reported for the GDMS technique are relative to copper (assumed to be $100 \%$ ), while those for TIMS are absolute values (derived from the known ${ }^{233} \mathrm{U}$ spike).

To rectify these differences, the samples that had initially been analyzed using GDMS were reanalyzed using the TIMS procedure. The results are shown in Table 5 as "TIMS-2." Much closer agreement was found between the TIMS-2 and GDMS results. Apparently, substantial spatial inhomogeneity exists across the individual sample meshes. When the identical portion of each loaded mesh was analyzed using the two methods, the results were comparable. Indeed, the ${ }^{235} \mathrm{U} /{ }^{238} \mathrm{U}$ isotope ratios show intrasample differences of only approximately $20-30 \%$, which is good agreement for smears of inhomogeneous surface contamination. 
Table 5. Comparison of uranium analyses for radiologic al glovebox smears using GDMS, TIMS of a separate portion of each loaded mesh sample (TIMS-1), and TIMS of the same portion of the loaded mesh initially used for GDMS (TIMS-2). Concentrations a re relative to copper (assumed to be $100 \%$ ) for GDMS and absolute for TIMS (determined using a ${ }^{233} \mathrm{U}$ spike). (ND = not determined.)

\begin{tabular}{|c|c|c|c|c|c|c|}
\hline Sample & Method & $\begin{array}{c}\text { Total } \\
\text { uranium } \\
(p p m)\end{array}$ & ${ }^{235} U /{ }^{238} U$ & $\begin{array}{l}{ }^{233} U \\
(\%)\end{array}$ & $\begin{array}{l}{ }^{235} U \\
(\%)\end{array}$ & $\begin{array}{c}{ }^{238} U \\
(\%)\end{array}$ \\
\hline$A$ & $\begin{array}{l}\text { GDMS } \\
\text { TIMS-1 } \\
\text { TIMS-2 }\end{array}$ & $\begin{array}{l}0.59 \\
0.027 \\
\text { ND }\end{array}$ & $\begin{array}{l}0.0999 \\
0.0059 \\
0.118\end{array}$ & $\begin{array}{l}\text { ND } \\
0.38 \\
0.98\end{array}$ & $\begin{array}{c}9.090 \\
0.570 \\
10.35\end{array}$ & $\begin{array}{l}90.91 \\
99.03 \\
88.49\end{array}$ \\
\hline$B$ & $\begin{array}{l}\text { GDMS } \\
\text { TIMS-1 } \\
\text { TIMS-2 }\end{array}$ & $\begin{array}{l}0.035 \\
0.012 \\
\text { NA }\end{array}$ & $\begin{array}{l}0.3236 \\
0.087 \\
0.227\end{array}$ & $\begin{array}{l}51.38 \\
53.18 \\
47.82\end{array}$ & $\begin{array}{r}12.34 \\
3.63 \\
9.43\end{array}$ & $\begin{array}{l}36.28 \\
42.33 \\
41.98\end{array}$ \\
\hline C & $\begin{array}{l}\text { GDMS } \\
\text { TIMS-1 } \\
\text { TIMS-2 }\end{array}$ & $\begin{array}{l}70 \\
84 \\
\text { ND }\end{array}$ & $\begin{array}{l}0.0694 \\
0.075 \\
0.054\end{array}$ & $\begin{array}{l}98.26 \\
98.32 \\
98.32\end{array}$ & $\begin{array}{l}0.042 \\
0.042 \\
0.031\end{array}$ & $\begin{array}{l}0.56 \\
0.57 \\
0.58\end{array}$ \\
\hline
\end{tabular}

An additional set of analyses was conducted to ascertain the ability to recover uranium contamination from painted surfaces. Samples using latex paint on aluminum sheet were prepared as surrogates for painted walls. The surrogates were doped using an acidic uranyl nitrate solution to be able to load 200- or 400- $\mu$ g uranium either above or below the paint layer. For the below-the-paint-layer loading, the uranium was applied to the metal surface before the paint was applied. In each case, three layers of paint were used. The uranium solution was prepared using NIST 010, a standard reference material with a 0.01014 certified ${ }^{235} \mathrm{U} /{ }^{238} \mathrm{U}$ isotope ratio. The painted surfaces were smeared using copper mesh and subsequently analyzed using GDMS and TIMS. For the below-the-paint-layer loadings, the surface was rubbed with sufficient vigor to remove a portion of the paint. The analysis results are presented in Table 6. Good agreement was observed for the elemental analyses. For example, the replicate $200-\mu \mathrm{g}$ paint loadings yielded 13 and 4 ppm uranium, respectively, which is in close agreement, considering the sampling approach used. TIMS analysis of the same smears yielded 18 and $2 \mathrm{ppm}$, confirming the GDMS results against a more accepted method. Insufficient signal was obtained for a GDMS isotopic analysis of the smear corresponding to the $200-\mu \mathrm{g}$ uranium sample placed under the paint layer. 
Table 6. Uranium analyses for smears of painted surfaces. NIST 010 is a ura nium standard with a $0.01014{ }^{235} \mathrm{U} /{ }^{238} \mathrm{U}$ reference value. (ND = not determined).

\begin{tabular}{|l|l|l|l|l|}
\hline \multicolumn{1}{|c|}{ Sample } & $\begin{array}{c}\text { GDMS U } \\
\text { elemental } \\
(\mathbf{p p m})\end{array}$ & \multicolumn{1}{|c|}{$\begin{array}{c}\text { GDMS } \\
{ }^{235} \mathbf{U} /{ }^{238} \mathbf{U}\end{array}$} & $\begin{array}{c}\text { TIMS U } \\
\text { elemental } \\
(\mathbf{p p m})\end{array}$ & $\begin{array}{c}\text { TIMS } \\
{ }^{235} \mathbf{U} /{ }^{238} \mathbf{U}\end{array}$ \\
\hline $\begin{array}{l}200 \mu \mathrm{g} \text { NIST 010 } \\
\text { on top of 3 layers } \\
\text { of paint }\end{array}$ & 13 & 0.0097 & 18 & 0.0099 \\
$\begin{array}{l}200 \mu \mathrm{g} \text { NIST 010 } \\
\text { on top of 3 layers } \\
\text { of paint }\end{array}$ & 4 & 0.0102 & 2 & 0.0101 \\
$\begin{array}{l}200 \mu \mathrm{g} \text { NIST 010 } \\
\text { beneath 3 layers } \\
\text { of paint }\end{array}$ & 0.069 & ND & 0.108 & 0.0122 \\
$\begin{array}{l}400 \mu \mathrm{g} \text { NIST } \\
\text { beneath 3 layers } \\
\text { of paint }\end{array}$ & 2 & 0.0104 & 2 & 0.0101 \\
$\begin{array}{l}\text { Blank copper } \\
\text { mesh }\end{array}$ & ND & ND & 0.017 & 0.0120 \\
\hline
\end{tabular}




\section{FUTURE STUDIES}

Future studies include additional optical (laser-induced fluorescence and optogalvanic spectroscopy) and mass spectrometric (SIMS and laser ablation) techniques. Spontaneous optical emission investigated to date is simple but not necessarily of high sensitivity. Laser-excited techniques, such as laser-induced fluorescence and optogalvanic spectroscopy, should provide lower detection limits.

The sample spatial inhomogeneity observed for metal mesh smears of real surfaces indicates that SIMS will be a fruitful analytical method. Because the SIMS technique inherently yields spatial information about the sample, we should be able to detect minute quantities of analytes otherwise masked for techniques that yield sampleaveraged results. For example, a few grains of highly enriched uranium in an otherwise natural abundance sample would be apparent in a SIMS image of a loaded metal mesh sample, but it might be lost in a measurement that only yields a single isotope ratio for the entire sample. The conducting metal mesh (or foil) medium will circumvent the sample charging problem common for SIMS analysis of insulators. The spatial imaging arguments apply as well to laser ablation mass spectrometry, wherein the laser focal spot would be rastered over the loaded mesh surface and ion current data collected at each location.

Other sample types that could benefit from the metal mesh medium for analytical determinations also are being explored. These sample types include Savannah River Site precipitator substrates and LANL stainless steel wool from magnetic gradient particle separations.

Staff at the Savannah River Site have developed an electrostatic precipitator for collection of particulate samples from air; their substrate is typically high purity silicon. We provided them with copper and silver mesh samples as replacement substrates for their precipitator, and they loaded them with $0.1-\mu \mathrm{g}$ uranium by precipitation of airborne particles. We are currently using the glow discharge mass spectrometer to conduct a uranium elemental and isotopic analysis of the loaded meshes.

LANL staff are exploring a high magnetic field gradient separator using stainless steel wools for removal of actinide oxide particles from dilute, liquid suspensions; however, it has been difficult to remove the trapped particles for analysis. We will determine if the glow discharge method can be used to analyze the loaded wools without removal of the particles. LANL supplied a sample of their wool medium (blank, no loading), and we have developed a simple means to fashion a robust cathode from it. An argon glow discharge using this cathode is electrically and optically stable. Experiments are under way to load this wool medium to conduct analytical sensitivity measurements.

Other research topics also will be examined. Use of trace alloy constituents of metal mesh media as internal standards will be explored for quantification of both optical and mass spectrometric methods. Use of metal mesh media for forensics sampling also will be evaluated. 


\section{CONCLUSIONS}

Metal mesh sampling is viable for both optical and mass spectrometric analyses. Discharges struck using mesh cathodes are stable and are not plagued by excessive arcing. Samples loaded either from solution or by rubbing contaminated surfaces persist for sufficient discharge time for analyses to be completed. The analytical sensitivity observed to date is in the 100-ng (mass spectrometry) to $10-\mu \mathrm{g}$ (optical emission) range. GDMS yields elemental and isotopic data that compares favorably with TIMS results. Spatial inhomogeneity across the loaded mesh sample was observed, indicating that imaging methods (e.g., SIMS or laser ablation mass spectrometry) bear examination. Additional spectroscopic methods, as well as other sample types, will be investigated in future studies. 


\section{REFERENCES}

1. R. W. Shaw, C. M. Barshick, J. P. Young, and J. M. Ramsey, Glow Discharge Instrument for Uranium Isotopic Analysis: Final Report, K/KNSP-480, National Security Program Office Report, Oak Ridge, Tennessee, June 1997.

2. J. A. C. Broekaert, "Atomic Emission Spectrometry," in Glow Discharge

Spectroscopies, R. K. Markus, ed., Plenum Press, New York, 1993, pp. 113-174.

3. B. A. Palmer, R. A. Keller, and R. Engleman, Jr., An Atlas of Uranium Emission Intensities in a Hollow Cathode Discharge, LA-2851-MS, Los Alamos National Laboratory Report, Los Alamos, New Mexico, July 1980. 